\title{
Isolation and partial characterization of a biosurfactant produced by Streptococcus thermophilus A
}

\author{
Lígia R. Rodrigues ${ }^{\mathrm{a}, *}$, José A. Teixeira ${ }^{\mathrm{a}}$, Henny C. van der Mei ${ }^{\mathrm{b}}$, Rosário Oliveira ${ }^{\mathrm{a}}$ \\ ${ }^{a}$ Centro de Engenharia Biológica, Universidade do Minho, Campus de Gualtar, 4710-057 Braga, Portugal \\ ${ }^{\mathrm{b}}$ Department of Biomedical Engineering, University Medical Center Groningen, and University of Groningen, \\ Antonius Deusinglaan 1, 9713 AV Groningen, The Netherlands
}

Received 7 May 2006; received in revised form 10 August 2006; accepted 10 August 2006

\begin{abstract}
Isolation and characterization of the surface active components from the crude biosurfactant produced by Streptococcus thermophilus A was studied. A fraction rich in glycolipids was obtained by the fractionation of crude biosurfactant using hydrophobic interaction chromatography. Molecular (by Fourier transform infrared spectroscopy) and elemental compositions (by X-ray photoelectron spectroscopy) were determined. Critical micelle concentration achieved was $20 \mathrm{~g} / \mathrm{l}$, allowing for a surface tension value of $36 \mathrm{~mJ} / \mathrm{m}^{2}$. Moreover, this glycolipid rich fraction was found to be an anti-adhesive and antimicrobial agent against several bacterial and yeast strains isolated from explanted voice prostheses. Further purification steps should be carefully analyzed as each purification step will increase the costs and decreases the amounts of biosurfactants recovered. (C) 2006 Elsevier B.V. All rights reserved.
\end{abstract}

Keywords: Biosurfactant; Isolation; Physicochemical characterization; Glycolipid

\section{Introduction}

Biosurfactants are surface-active compounds released by microorganisms that exhibit surface activity and have been described as antimicrobial and anti-adhesive agents. A broad diversity of chemical structures, such as glycolipids, lipopeptides, polysaccharide-protein complexes, protein-like substances, lipopolysaccharides, phospholipids, fatty acids and neutral lipids, have been attributed to biosurfactants [1-5]. It is, therefore, reasonable to expect diverse properties and physiological functions for different groups of biosurfactants. Adsorption of biosurfactants to a substratum surface alters the hydrophobicity of the surface interfering in the microbial adhesion and desorption processes [6]. For example, a dairy Streptococcus thermophilus strain isolated from a heat-exchanger plate in the downward section of a pasteurizer was found to produce a biosurfactant which caused its own desorption from glass, leaving a completely non-adhesive coating [7]. Active bioyogurt contain-

\footnotetext{
* Corresponding author at: Centro de Engenharia Biológica, IBQF, Universidade do Minho, Largo do Paço, 4719 Braga Codex, Portugal. Tel.: +351 253 604400; fax: +351253678986.

E-mail address: 1rmr@deb.uminho.pt (L.R. Rodrigues).
}

ing active $S$. thermophilus has been suggested to have beneficial effects in prolonging the lifetime of indwelling voice prostheses. The mechanism by which this occurs has not been investigated, but it is hypothesized that the presence of $S$. thermophilus and Lactobacillus bulgaricus, two well-known probiotic bacterial strains, in active bioyogurt may interfere with the microbial adhesion to the silicone rubber $[8,9]$. These results were confirmed by artificial throat model experiments with the cited probiotic bacteria [10]. Moreover, S. thermophilus A was found to be a biosurfactant-producer and the adsorption of its biosurfactant onto silicone rubber surfaces was effective in decreasing the initial deposition rates, as well as the number of bacterial cells adhering after $4 \mathrm{~h}$, for several microbial strains isolated from explanted voice prostheses [11]. A role for biosurfactants as defense weapons in postadhesion competition with other strains or species has been suggested for biosurfactants released by oral Streptococcus mitis strains against Streptococcus mutans adhesion [12] and for biosurfactants released by lactobacilli against adhesion of uropathogens [13-15]. Additionally, the biosurfactants produced by $S$. mitis BMS were found to play a protective role against adhesion of cariogenic bacteria [16,17].

Despite some well know biosurfactants, as for example, surfactin produced by Bacillus subtilis [18,19], rhamnolipids 
produced by Pseudomonas aeruginosa [20], mannosylerythritol lipids produced by Candida antartica [21] or succinoyl trehalose lipids produced by Rodococcus erythropolis [22,23], information on the chemical structure of biosurfactants produced by probiotic microorganisms is limited. Biosurfactants produced by $S$. thermophilus strains have not been extensively studied and further characterization is needed, but thin layer chromatograms (TLC) has indicated that the crude product is a mixture of various components, with a glycolipid-like component being the most surface active [7,24].

The aim of the present study was to isolate and characterize the surface active component from the crude biosurfactant mixture produced by $S$. thermophilus A. This surface active component was further characterized by the determination of its molecular (by Fourier transform infrared spectroscopy) and elemental composition (by X-ray photoelectron spectroscopy). Moreover, the functional characterization was established using the following techniques: critical micelle concentration determination, $\mathrm{pH}$ stability, antimicrobial activity and anti-adhesion test.

\section{Materials and methods}

\subsection{Microbial strains and culture conditions}

The bacterial strain $S$. thermophilus A obtained from NIZO (The Netherlands) was stored at $-20^{\circ} \mathrm{C}$ in conventional M17 broth (OXOID, Basingstoke, England) containing 15\% (v/v) glycerol solution until ready to use. From frozen stock, bacteria were streaked on M17 agar plates and incubated at $37{ }^{\circ} \mathrm{C}$ for further culturing. To prepare subcultures, the medium was inoculated with a colony from the plate and incubated overnight under the same conditions.

Four bacterial strains: Staphylococcus epidermidis GB 9/6, Streptococcus salivarius GB 24/9, Staphylococcus aureus GB 2/1 and Rothia dentocariosa GBJ 52/2B and two yeast strains: Candida albicans GBJ 13/4A and Candida tropicalis GB 9/9 isolated from explanted voice prostheses were used in the antiadhesion and antimicrobial assays. The choice of the microorganisms was based on several studies on the biodeterioration of silicone rubber, which allowed the establishment of the commonly found microflora on failed explanted silicone rubber voice prostheses [25-28]. All strains were first grown overnight at $37^{\circ} \mathrm{C}$ in ambient air on agar plates from frozen stocks, the agar plates were kept at $4{ }^{\circ} \mathrm{C}$, never longer than 2 weeks. Several colonies were used to inoculate $10 \mathrm{ml}$ of brain heart infusion broth (BHI, OXOID, Basingstoke, England) for all the bacterial and yeast strains in use. This preculture was incubated at $37^{\circ} \mathrm{C}$ in ambient air for $24 \mathrm{~h}$ and used to inoculate a second culture of $200 \mathrm{ml}$ that was grown statically for $18 \mathrm{~h}$. The microorganisms from the second culture were harvested by centrifugation for $5 \mathrm{~min}$ at $10,000 \times g$ and washed twice with demineralized water. Subsequently, bacterial cells were suspended in $200 \mathrm{ml}$ phosphate buffer saline (PBS: $10 \mathrm{mM} \mathrm{KH}_{2} \mathrm{PO}_{4} / \mathrm{K}_{2} \mathrm{HPO}_{4}$ and $150 \mathrm{mM} \mathrm{NaCl}$ with $\mathrm{pH}$ adjusted to 7.0 , ionic strength $(\mu)=0.19 \mathrm{M})$, after sonication on ice $(10 \mathrm{~s})$, to a concentration of $3 \times 10^{8} \mathrm{ml}^{-1}$. The sonication procedure did not promote cell lysis. Yeasts were suspended in PBS to a concentration of $3 \times 10^{6} \mathrm{ml}^{-1}$. A Bürker-Türk counting chamber was used to count the cells.

\subsection{Biosurfactant production and isolation}

The production of crude biosurfactant obtained from $S$. thermophilus A is described elsewhere [11,29]. Briefly, $600 \mathrm{ml}$ of M17 broth was incubated with $15 \mathrm{ml}$ of an overnight $S$. thermophilus A subculture and incubated for $18 \mathrm{~h}$. Cells were harvested by centrifugation $\left(10,000 \times g, 5 \mathrm{~min}\right.$ and $\left.10^{\circ} \mathrm{C}\right)$, washed twice in demineralized water, and resuspended in $100 \mathrm{ml}$ PBS. The bacteria were left at room temperature for $2 \mathrm{~h}$ with gentle stirring for biosurfactant release. Subsequently, the bacteria were removed by centrifugation and the remaining supernatant liquid was filtered through a $0.22 \mu \mathrm{m}$ pore-size filter (Millipore). The supernatant was dialyzed against demineralized water at $4^{\circ} \mathrm{C}$ in a Spectrapor membrane tube (molecular weight cut off 6000-8000, Spectrum Medical Industries Inc., CA) and freezedried.

\subsection{Hydrophobic interaction chromatography}

Hydrophobic interaction chromatography (HIC) separates biomolecules by the strength of their interaction with hydrophobic ligands attached to an uncharged base matrix. Samples bind at high ionic strength and are eluted as the ionic strength is lowered. Fractionation was performed on an Octyl Sepharose 4 FF Prep hydrophobic interaction column $(20 \mathrm{ml}$, Pharmacia Biotech). Freeze-dried crude biosurfactant $(100 \mathrm{~g} / \mathrm{l})$ was prepared in a PBS buffer solution (pH 7.0) containing $1.0 \mathrm{M}$ $\left(\mathrm{NH}_{4}\right)_{2} \mathrm{SO}_{4}$ and loaded $(500 \mu \mathrm{l})$ onto the column equilibrated in the same buffer. Elution was carried out with a $60 \mathrm{ml}$ linear gradient from 1 to $0 \mathrm{M}\left(\mathrm{NH}_{4}\right)_{2} \mathrm{SO}_{4}$ in PBS buffer (flow rate, $60 \mathrm{ml} / \mathrm{h}$; fractions, $2.5 \mathrm{ml}$ ). Absorbance at $280 \mathrm{~nm}$ was recorded, using a L-7455 Diode-Array detector (Merck), and analysed with D7000 HPLC System Manager (Version 3.1) Software. The protein content of the eluted fractions was determined according to the Bradford method with Coomassie brilliant blue using bovine serum albumin as the standard. The total sugar content of the eluted fractions was evaluated by the phenol-sulphuric method described by Dubois et al. [30] using glucose as the standard. All the fractions eluted were tested for surface activity by measuring the surface tension of the samples with the Ring method, as described elsewhere [31]. Three fractions were obtained from this fractionation procedure (A, B and C). The isolated fractions were dialyzed against demineralized water at $4{ }^{\circ} \mathrm{C}$ in a Spectrapor membrane tube (molecular weight cut off 6000-8000, Spectrum Medical Industries Inc., CA) and freeze-dried.

\subsection{Critical micelle concentration ( $\mathrm{cmc}$ ) and biosurfactant stability}

Critical micelle concentration $(\mathrm{cmc})$ is the concentration of an amphiphilic component in solution at which the formation of micelles in the solution is initiated. It is important for several applications of biosurfactants to establish their $\mathrm{cmc}$, as above 
this concentration no further effect is expected in the surface activity. The $c m c$ was determined by plotting the surface tension as a function of the logarithm of biosurfactant concentration and is found as the intersection between the two lines that best fit through the pre- and post-cmc data. Concentrations ranging from 2.5 to $40 \mathrm{~g} / \mathrm{l}$ of the crude biosurfactant and isolated fractions were prepared in PBS. The surface tension of each sample was determined by the Ring method [31] using a KRUSS Tensiometer equipped with a $1.9 \mathrm{~cm}$ De Noüy platinum ring at room temperature $\left(25 \pm 1^{\circ} \mathrm{C}\right)$. Measurements were done in triplicate.

The applicability of the biosurfactants as coating agents for voice prostheses, for example, can be conditioned by its stability to $\mathrm{pH}$ changes; thus crude biosurfactant and isolated fractions were prepared with a $40 \mathrm{~g} / \mathrm{l}$ concentration at several $\mathrm{pH}(\mathrm{pH}$ $4-10, \mathrm{PBS}, \mu=0.19 \mathrm{M})$. To determine the $\mathrm{pH}$ stability of the crude biosurfactant and isolated fractions the surface tension was measured by the Ring method [31].

\subsection{Fourier transform infrared spectroscopy}

Fourier transform infrared spectroscopy (FT-IR) is an analytical technique used to identify organic (and in some cases inorganic) materials. This technique measures the absorption of various infrared light wavelengths by the material of interest. These infrared absorption bands identify specific molecular components and structures. For further characterization, $1 \mathrm{mg}$ of freeze-dried crude biosurfactant and isolated fraction $\mathrm{C}$ were ground with $100 \mathrm{mg}$ of $\mathrm{KBr}$ and pressed with $7500 \mathrm{~kg}$ for $30 \mathrm{~s}$ to obtain translucent pellets. Infrared absorption spectra were recorded on a FT-IR/Diffus Bomem MB spectrometer with a spectral resolution and wave number accuracy of 4 and $0.01 \mathrm{~cm}^{-1}$, respectively. All measurements consisted of 500 scans, and a $\mathrm{KBr}$ pellet was used as the background reference. Quantification of a spectral region of interest was obtained by normalizing of the area under the absorption bands with respect to the area of the $\mathrm{CH}$ absorption band around $2920 \mathrm{~cm}^{-1}$.

\subsection{X-ray photoelectron spectroscopy}

X-ray photoelectron spectroscopy (XPS) is a surface sensitive analytic technique to determine the elemental composition at a solid surface by measuring the energy of electrons emitted in response to an X-ray source. Freeze-dried crude biosurfactant and isolated fraction $\mathrm{C}$ were dissolved in demineralized water $(30 \mathrm{~g} / \mathrm{l})$ and $10 \mu \mathrm{l}$ droplets were placed on gold-coated glass slides $(1 \mathrm{~cm} \times 1 \mathrm{~cm})$. After air-drying, glass slides were inserted into the chamber of the spectrometer (Surface Science Instruments, S-probe). The residual pressure in the spectrometer was approximately $10^{-9} \mathrm{~Pa}$. A magnesium anode and quartz monochromator (Al $\mathrm{K} \alpha$ source) was used for X-ray production $(10 \mathrm{kV}$ and $22 \mathrm{~mA})$ at a spot size of $250 \mu \mathrm{m} \times 1000 \mu \mathrm{m}$. After a scan of the overall spectrum in the binding energy range $1-1100 \mathrm{eV}$ at low resolution ( $150 \mathrm{eV}$ pass energy), peaks over a $20 \mathrm{eV}$ binding energy range were recorded at high resolution (50 eV pass energy) in the following order: $\mathrm{C} 1 \mathrm{~s}, \mathrm{O} 1 \mathrm{~s}, \mathrm{~N} 1 \mathrm{~s}, \mathrm{P}$ $2 \mathrm{p}$ and $\mathrm{C} 1 \mathrm{~s}$ again in order to be able to account for contamination or deterioration of the samples caused by X-ray irradiation.
The areas under the peaks, after correction with instrument sensitivity factors, were used to calculate the elemental surface concentration ratios $\mathrm{N} / \mathrm{C}, \mathrm{O} / \mathrm{C}$ and $\mathrm{P} / \mathrm{C}$.

The $\mathrm{C}$ 1s peak was decomposed by a least-squares fitting program into four Gaussian components set at $284.5 \mathrm{eV}$ (C1), $285.9 \mathrm{eV}(\mathrm{C} 2), 287.3 \mathrm{eV}(\mathrm{C} 3)$ and $289.2 \mathrm{eV}$ (C4) by imposing a constant full width at half maximum of $1.35 \mathrm{eV}$; these four components were thought to be representative of the carbon involved in $\mathrm{C}-\mathrm{C}$ and $\mathrm{C}-\mathrm{H}$ bonds, $\mathrm{C}-\mathrm{O}$ and $\mathrm{C}-\mathrm{N}$ bonds (including ether, alcohol, amine or amide [32] $),(\mathrm{C}=\mathrm{O})-\mathrm{N}$ and $(\mathrm{C}=\mathrm{O})-\mathrm{O}$ bonds (including amide, carbonyl, carboxylate, acetal or hemiacetal or amide [28]), and $(\mathrm{C}=\mathrm{O})-\mathrm{OH}$, respectively. The oxygen peak was split into two components at $530.33 \mathrm{eV}(\mathrm{O} 1)$ and $531.83 \mathrm{eV}(\mathrm{O} 2)$ by imposing a constant full width at half maximum of $1.70 \mathrm{eV}$ and thought to be representative of oxygen involved in $\mathrm{O}=\mathrm{C}$ and $\mathrm{C}-\mathrm{O}$ bonds, respectively.

\subsection{Anti-adhesion assay in 96 wells plate}

The anti-adhesive activity of the crude biosurfactant and isolated fraction $\mathrm{C}$ against the bacterial strains: $S$. epidermidis GB 9/6, S. salivarius GB 24/9, S. aureus GB 2/1, and $R$. dentocariosa GBJ 52/2B and the yeast strains: C. albicans GBJ 13/4A and $C$. tropicalis GB 9/9 isolated from explanted voice prostheses was quantified according to a previously reported adhesion assay [15,33]. In a few words, the wells of a sterile 96-well flat-bottomed plastic tissue culture plate with a lid were filled with $200 \mu \mathrm{l}$ of the crude biosurfactant and isolated fraction $\mathrm{C}$ to be tested for anti-adhesive activity. Several concentrations were tested ranging from 2.5 to $40 \mathrm{~g} / \mathrm{l}$. This concentration range was established according to previous studies [11,34] and also to results presented in Fig. 2. The plate was incubated for $18 \mathrm{~h}$ at $4{ }^{\circ} \mathrm{C}$ and subsequently washed twice with PBS. Control wells contained buffer (PBS) only. An aliquot of $200 \mu 1$ of a washed bacterial or yeast suspension was added and incubated in the wells for $4 \mathrm{~h}$ at $4{ }^{\circ} \mathrm{C}$. Unattached organisms were removed by washing the wells three times with PBS. The adherent microorganisms were fixed with $200 \mu \mathrm{l}$ of $99 \%$ methanol per well, and after $15 \mathrm{~min}$ the plates were emptied and left to dry. Then the plates were stained for 5 min with $200 \mu$ l of $2 \%$ crystal violet used for Gram staining per well. Excess stain was rinsed of by placing the plate under running tap water. After the plates were air dried, the dye bound to the adherent microorganisms was resolubilized with $200 \mu \mathrm{l}$ of $33 \%$ (v/v) glacial acetic acid per well and the optical density readings of each well were taken at $595 \mathrm{~nm}$. The microtiter-plate anti-adhesion assay allows the estimation of the crude biosurfactant and isolated fraction $\mathrm{C}$ concentrations that are effective in inhibiting adhesion of the microorganisms studied.

\subsection{Antimicrobial assay}

The microorganisms used for the antimicrobial assay were the same as used in the anti-adhesion assay in 96 wells plate described above. The growth inhibition test was performed as described by Elving et al. [35]. Briefly, yeasts and bacteria cultured overnight under appropriate conditions were harvested 
by centrifugation and diluted in reduced transport fluid (RTF: $0.9 \mathrm{~g} / 1 \mathrm{NaCl}, 0.9 \mathrm{~g} / \mathrm{l}\left(\mathrm{NH}_{4}\right)_{2} \mathrm{SO}_{4}, 0.45 \mathrm{~g} / \mathrm{KH}_{2} \mathrm{PO}_{4}, 0.19 \mathrm{~g} / \mathrm{l}$ $\mathrm{MgSO}_{4}, 0.45 \mathrm{~g} / 1 \mathrm{~K}_{2} \mathrm{HPO}_{4}, 0.37 \mathrm{~g} / \mathrm{l} \mathrm{Na} 2$ EDTA, $0.2 \mathrm{~g} / \mathrm{l}$ L-cysteine $\mathrm{HCl}, \mathrm{pH}$ 6.8) to a concentration allowing confluent growth when plated with a cotton swab on the agar. Yeasts were plated on MRS agar (OXOID, Basingstoke, England), while bacteria were plated on brain heart infusion agar (OXOID, Basingstoke, England). Agar plates were dried for $20 \mathrm{~min}$ at room temperature and $5 \mu \mathrm{l}$ of the isolated fraction $\mathrm{C}$ of several concentrations (ranging from 2.5 to $40 \mathrm{~g} / \mathrm{l}$ according to Fig. 2 and previous studies [11,34]), were spotted onto the surface of the agar plate. After overnight incubation, the agar plates were screened for growth inhibition zones around the isolated fraction spots.

\section{Results}

\subsection{Partial purification of the biosurfactants}

The fractionation profile of the crude biosurfactant obtained from S. thermophilus A, concerning total protein and total sugar content, absorbance at $280 \mathrm{~nm}$ and surface tension, is presented in Fig. 1. The crude biosurfactant showed a surface tension of $37 \mathrm{~mJ} / \mathrm{m}^{2}$; an absorbance at $280 \mathrm{~nm}$ of 2.876 ; a total sugar content of $0.189 \mathrm{~g} / \mathrm{l}$; a total protein content of $0.325 \mathrm{~g} / \mathrm{l}$. The fractionation procedure allowed the isolation of three distinct
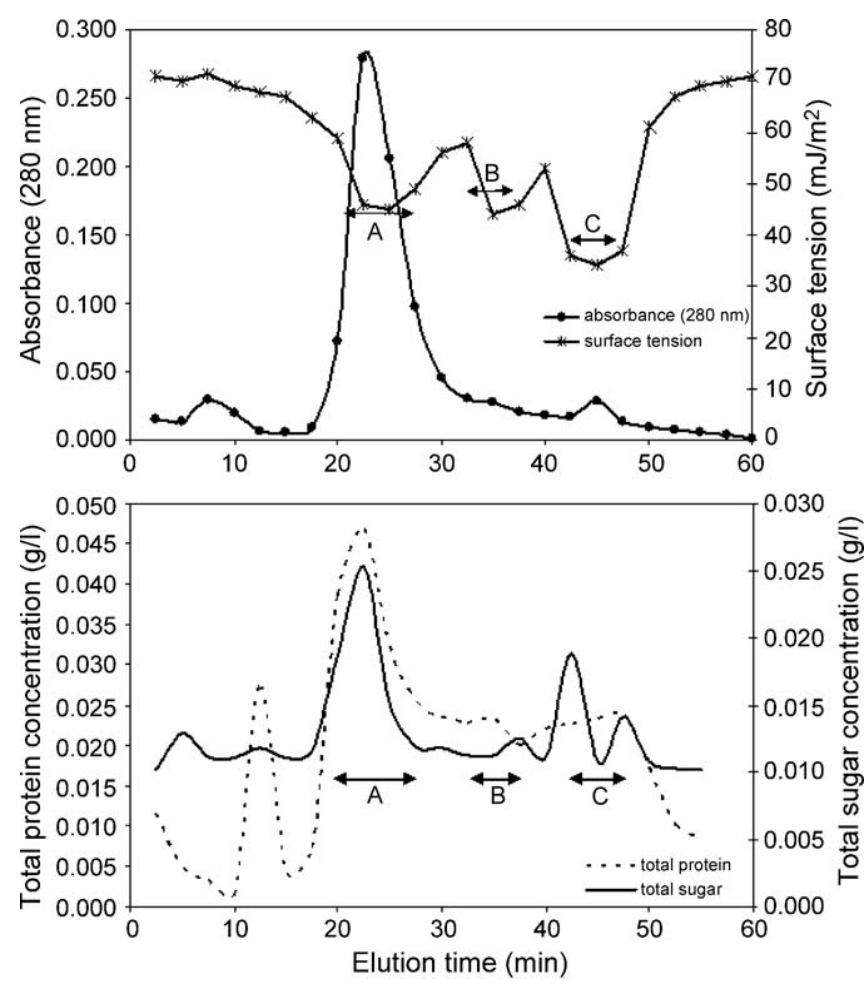

Fig. 1. Elution profile of the crude biosurfactant obtained from Streptococcus thermophilus A on Octyl Sepharose 4 FF Prep column. Fractions were eluted with a linear gradient from 1 to $0 \mathrm{M}\left(\mathrm{NH}_{4}\right)_{2} \mathrm{SO}_{4}$ in PBS buffer. Fractions were collected and monitored by absorbance at $280 \mathrm{~nm}$ record, total sugars (phenol-sulfuric method), total protein (Bradford method) and surface tension (Ring method). Results represent the average of three independent experiments.

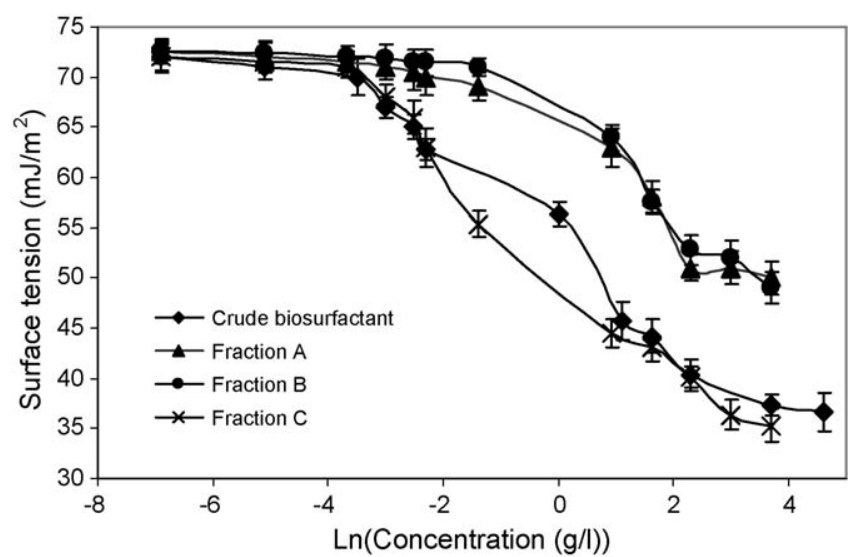

Fig. 2. Surface tension vs. logarithm of the concentrations of crude biosurfactant and isolated fractions obtained from S. thermophilus A. Results represent the average of three independent experiments.

fractions with surface activity, fraction $\mathrm{A}$ (from 20 to $27.5 \mathrm{~min}$ ), fraction $\mathrm{B}$ (from 32.5 to $37.5 \mathrm{~min}$ ) and fraction $\mathrm{C}$ (from 42.5 to $47.5 \mathrm{~min}$ ) with surface tensions 50,49 and $36 \mathrm{~mJ} / \mathrm{m}^{2}$, respectively. All the fractions A, B and C exhibited low contents of total sugar $(0.018,0.012$ and $0.015 \mathrm{~g} / \mathrm{l}$, respectively) and total protein $(0.036,0.022$ and $0.023 \mathrm{~g} / \mathrm{l}$, respectively). The relative percentages of each fraction present in the crude biosurfactant were $40 \%$ for fraction A, 30\% for fraction B, $20 \%$ for fraction $\mathrm{C}$, and $10 \%$ for other fractions not collected.

\subsection{Critical micelle concentration ( $\mathrm{cmc}$ ) and biosurfactant stability}

The critical micelle concentration $(\mathrm{cmc})$ for the crude biosurfactant and isolated fractions (A, B and C) is illustrated in Fig. 2. Fraction $\mathrm{C}$ was found to be the most surface active sample, with cmc of $20 \mathrm{~g} / \mathrm{l}$, thus similar to the crude biosurfactant. Fractions $\mathrm{A}$ and $\mathrm{B}$ showed smaller decreases in the surface tensions with increasing concentrations.

Crude biosurfactant and fraction $\mathrm{C}$ surface tension reducing activity was relatively stable to $\mathrm{pH}$ changes (Table 1 ). The surface tensions remained stable over a $\mathrm{pH}$ range from 5 to 9 , although there was a slight increase at pH's 4 and 10. Both crude biosurfactant and isolated fraction $\mathrm{C}$ became turbid below $\mathrm{pH} 4$

Table 1

Surface tension measurements of crude biosurfactant or isolated fractions with a concentration of $40 \mathrm{~g} / \mathrm{l}$ at several $\mathrm{pH}$ values, as determined by the Ring method

\begin{tabular}{rllll}
\hline $\mathrm{pH}$ & \multicolumn{3}{l}{ Surface tension $\left(\mathrm{mJ} / \mathrm{m}^{2}\right)$} & \\
\cline { 2 - 5 } & Crude biosurfactant & Fraction A & Fraction B & Fraction C \\
\hline 4 & $39.4 \pm 2.0$ & $69.8 \pm 4.9$ & $71.8 \pm 6.5$ & $36.2 \pm 1.1$ \\
5 & $38.1 \pm 0.8$ & $68.8 \pm 2.8$ & $64.3 \pm 4.5$ & $35.8 \pm 1.1$ \\
6 & $37.2 \pm 1.1$ & $51.5 \pm 1.0$ & $48.7 \pm 3.4$ & $35.2 \pm 1.4$ \\
7 & $37.3 \pm 0.8$ & $50.2 \pm 4.0$ & $49.3 \pm 3.5$ & $35.3 \pm 3.2$ \\
8 & $37.1 \pm 0.7$ & $55.9 \pm 2.8$ & $56.9 \pm 4.0$ & $34.9 \pm 0.7$ \\
9 & $38.3 \pm 2.3$ & $71.2 \pm 5.0$ & $55.7 \pm 3.3$ & $35.1 \pm 2.1$ \\
10 & $41.4 \pm 7.5$ & $69.9 \pm 5.6$ & $65.8 \pm 11.8$ & $35.9 \pm 3.2$
\end{tabular}

Experiments were performed in triplicate. 


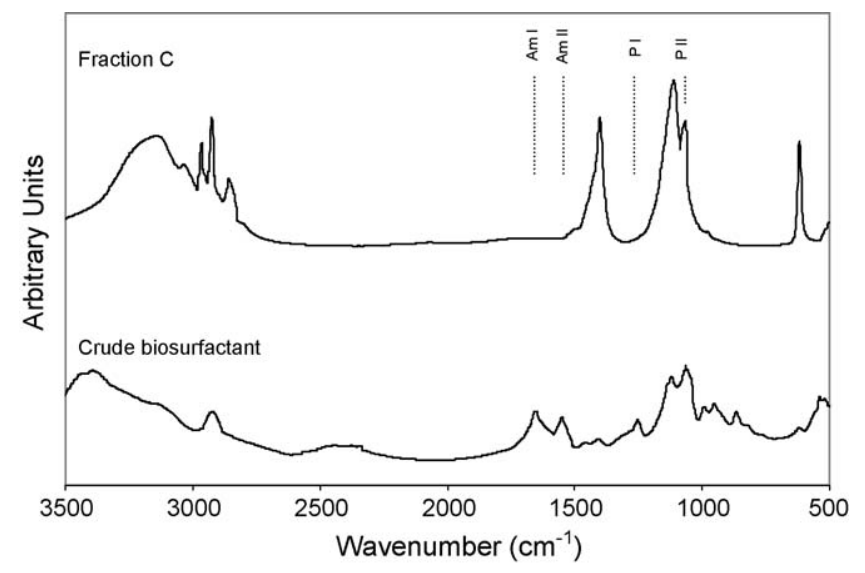

Fig. 3. Fourier transform infrared absorption spectra of crude biosurfactant and isolated fraction $\mathrm{C}$ obtained from $\mathrm{S}$. thermophilus $\mathrm{A}$. The absorption bands used for quantification are indicated.

due to precipitation. For fractions A and B the surface tensions were only stable between $\mathrm{pH} 6$ and 8 .

\subsection{Fourier transform infrared spectroscopy}

The molecular composition of the crude biosurfactant and isolated fraction $\mathrm{C}$ was evaluated by Fourier transform infrared spectroscopy. Fig. 3 presents the spectra of the freeze-dried samples. All of the spectra showed essentially the same adsorption bands, and only the relative areas under the various absorption bands differed. The most important bands were located at $2920 \mathrm{~cm}^{-1}$ (CH band: $\mathrm{CH}_{2}-\mathrm{CH}_{3}$ stretching), $1655 \mathrm{~cm}^{-1}$ (AmI band: $\mathrm{C}=\mathrm{O}$ stretching in proteins), $1551 \mathrm{~cm}^{-1}$ (AmII band: $\mathrm{N}-\mathrm{H}$ bending in proteins), $1254 \mathrm{~cm}^{-1}$ (PI band: phosphates) and $1065 \mathrm{~cm}^{-1}$ (PII band: polysaccharides). Absorption band ratios of AmI, AmII, PI and PII with respect to the $\mathrm{CH}$ band of 1.0, 0.9, 0.9 and 1.6, respectively, were obtained for the crude biosurfactant. For fraction $\mathrm{C}$ lower absorption band ratios were achieved for $\mathrm{PI} / \mathrm{CH}$ and $\mathrm{PII} / \mathrm{CH}(0.1$ and 1.0 , respectively), and no $\mathrm{AmI} / \mathrm{CH}$ and $\mathrm{AmII} / \mathrm{CH}$ absorption band ratios were found. From the crude biosurfactant spectra it was possible to confirm that it consists of a mixture of several compounds. Although the crude biosurfactant showed the AmI and AmII adsorption bands indicative of proteins presence, the fractionation procedure resulted in a fraction (fraction $\mathrm{C}$ ) with no protein content. Regarding fraction $\mathrm{C}$, the absorption bands between 1000 and $1200 \mathrm{~cm}^{-1}$ were attributed to ethereal and hydroxilic $\mathrm{C}-\mathrm{O}$ stretch vibrations and absorption bands present around 2965, 2920, 2860 and $1398 \mathrm{~cm}^{-1}$ that include $\left(-\mathrm{CH}_{3}\right)$ symmetric deformation vibrations, $(\mathrm{C}-\mathrm{H})$ bending vibrations of $\mathrm{CH}_{3}$ and $\mathrm{CH}_{2}$ groups and $\mathrm{CH}_{2}-\mathrm{CH}_{3}$ stretching vibrations are characteristic of polysaccharides.

\subsection{X-ray photoelectron spectroscopy}

X-ray photoelectron spectroscopy of the freeze-dried crude biosurfactant and fraction $\mathrm{C}$ yielded the elemental surface concentration ratio N/C, O/C, P/C and the components of the $\mathrm{C}$ $1 \mathrm{~s}$ and $\mathrm{O} 1 \mathrm{~s}$ peaks (Table 2). For both crude biosurfactant and fraction $\mathrm{C}$, although samples contained sizeable amounts of nitrogen, the N/C ratios measured were too low to be identified as pure protein. The $\mathrm{O} / \mathrm{C}$ ratios were also too high to indicate the presence of pure proteins and point to the presence of polysaccharides. This was in agreement with the FT-IR spectra presented in Fig. 3, where the AmI and AmII absorption bands indicative of proteins were not detected. The XPS data demonstrated that fraction $\mathrm{C}$ contained a higher percentage of carbon involved in $\mathrm{C} 2$ bonds and oxygen in $\mathrm{O} 2$ bonds, while nitrogen was absent. In fact the percentage of oxygen involved in $\mathrm{O} 2$ was too high for the material to be identified as a phospholipid, but on the basis of the XPS data and infrared absorption bands the material probably contains glycolipids.

\subsection{Anti-adhesive activity}

The anti-adhesive activity of the crude biosurfactant and isolated fractions was evaluated at several concentrations and compared against a variety of bacterial and yeast strains isolated

Table 2

Chemical composition data by XPS of crude biosurfactant, isolated fraction $\mathrm{C}$ and reference compounds (for comparison)

\begin{tabular}{|c|c|c|c|c|c|c|c|c|c|}
\hline \multirow[t]{2}{*}{ Compounds } & \multicolumn{3}{|c|}{ Elemental composition } & \multicolumn{6}{|c|}{ Fractions of $\mathrm{C}$ and $\mathrm{O}$ atoms } \\
\hline & $\mathrm{N} / \mathrm{C}$ & $\mathrm{O} / \mathrm{C}$ & $\mathrm{P} / \mathrm{C}$ & $\mathrm{C} 1$ & $\mathrm{C} 2$ & $\mathrm{C} 3$ & $\mathrm{C} 4$ & $\mathrm{O} 1$ & $\mathrm{O} 2$ \\
\hline Crude biosurfactant & 0.12 & 0.63 & 0.08 & 0.51 & 0.34 & 0.13 & 0.02 & 0.66 & 0.34 \\
\hline Fraction C & 0.00 & 0.60 & 0.03 & 0.37 & 0.41 & 0.19 & 0.03 & 0.41 & 0.59 \\
\hline \multicolumn{10}{|l|}{ Reference compounds } \\
\hline Glycosidic residue $^{\mathrm{a}}$ & 0.00 & 0.83 & 0.00 & 0.00 & 0.83 & $0.17^{\mathrm{b}}$ & & 0.00 & 1.00 \\
\hline Phospholipid $^{\mathrm{c}}$ & 0.01 & 0.21 & 0.03 & 0.82 & 0.13 & 0.05 & 0.01 & 0.37 & 0.63 \\
\hline Cholesterol & 0.00 & 0.03 & 0.00 & 0.87 & 0.12 & 0.00 & 0.00 & 0.00 & 1.00 \\
\hline LTA $^{\mathrm{d}}$ & 0.03 & 0.63 & 0.07 & 0.41 & 0.44 & 0.44 & 0.05 & 0.24 & 0.76 \\
\hline Protein ${ }^{\mathrm{e}}$ & 0.27 & 0.32 & 0.00 & 0.41 & 0.32 & $0.28^{\mathrm{b}}$ & & 0.86 & 0.14 \\
\hline Salivary glycoprotein ${ }^{f}$ & 0.18 & & & 0.52 & 0.32 & $0.16^{\mathrm{b}}$ & & & \\
\hline
\end{tabular}

${ }^{a}$ Glycosidic residue $\mathrm{C}_{6} \mathrm{H}_{10} \mathrm{O}_{5}$ [21].

b $\mathrm{C} 3$ and $\mathrm{C} 4$ together.

${ }^{c}$ L- $\alpha$-Phosphatidyl-DL-glycerol dimyristoyl [21].

${ }^{\mathrm{d}}$ Lipoteichoic acid from S. mutans (Sigma).

e Average protein, calculated for a collection of bacterial, fungal and mammalian proteins [21].

${ }^{\mathrm{f}}$ Data from Velraeds et al. [3]. 
Table 3

Microbial inhibition percentages obtained from the microtiter-plate anti-adhesion assay with several crude biosurfactant and isolated fraction C concentrations

\begin{tabular}{|c|c|c|c|c|c|c|}
\hline \multirow[t]{3}{*}{ Microorganisms } & \multicolumn{6}{|c|}{ Microbial adhesion inhibition (\%) } \\
\hline & \multirow{2}{*}{$\begin{array}{l}\text { Control } \\
\text { PBS }\end{array}$} & \multicolumn{5}{|c|}{ Crude biosurfactant (g/l) } \\
\hline & & 2.5 & 5 & 10 & 20 & 40 \\
\hline S. epidermidis GB $9 / 6$ & 0.0 & $28 \pm 4$ & $40 \pm 1$ & $62 \pm 1$ & $69 \pm 1$ & $70 \pm 4$ \\
\hline S. salivarius GB 24/9 & 0.0 & $-5 \pm 0$ & $24 \pm 1$ & $48 \pm 1$ & $56 \pm 2$ & $53 \pm 2$ \\
\hline S. aureus GB 2/1 & 0.0 & $11 \pm 1$ & $22 \pm 1$ & $42 \pm 0$ & $55 \pm 2$ & $56 \pm 2$ \\
\hline R. dentocariosa GBJ 52/2B & 0.0 & $-70 \pm 8$ & $12 \pm 1$ & $20 \pm 1$ & $31 \pm 1$ & $35 \pm 1$ \\
\hline C. albicans GBJ 13/4A & 0.0 & $-100 \pm 15$ & $-67 \pm 7$ & $-21 \pm 2$ & $4 \pm 0$ & $11 \pm 0$ \\
\hline C. tropicalis GB 9/9 & 0.0 & $-43 \pm 5$ & $-23 \pm 2$ & $-7 \pm 0$ & $8 \pm 0$ & $18 \pm 1$ \\
\hline \multirow[t]{3}{*}{ Microorganisms } & \multicolumn{6}{|c|}{ Microbial adhesion inhibition (\%) } \\
\hline & \multirow{2}{*}{$\begin{array}{l}\text { Control } \\
\text { PBS }\end{array}$} & \multicolumn{5}{|c|}{ Fraction C (g/l) } \\
\hline & & 2.5 & 5 & 10 & 20 & 40 \\
\hline S. epidermidis GB 9/6 & 0.0 & $34 \pm 3$ & $46 \pm 1$ & $65 \pm 1$ & $71 \pm 1$ & $77 \pm 4$ \\
\hline S. salivarius GB 24/9 & 0.0 & $2 \pm 0$ & $35 \pm 2$ & $51 \pm 1$ & $59 \pm 2$ & $62 \pm 3$ \\
\hline S. aureus GB 2/1 & 0.0 & $16 \pm 2$ & $22 \pm 1$ & $41 \pm 2$ & $52 \pm 2$ & $56 \pm 2$ \\
\hline R. dentocariosa GBJ 52/2B & 0.0 & $-55 \pm 7$ & $16 \pm 0$ & $21 \pm 1$ & $32 \pm 1$ & $36 \pm 1$ \\
\hline C. albicans GBJ 13/4A & 0.0 & $-88 \pm 11$ & $-43 \pm 5$ & $-12 \pm 1$ & $6 \pm 0$ & $15 \pm 0$ \\
\hline C. tropicalis $\mathrm{GB} 9 / 9$ & 0.0 & $-34 \pm 4$ & $-15 \pm 1$ & $3 \pm 0$ & $11 \pm 0$ & $23 \pm 1$ \\
\hline
\end{tabular}

PBS was used as control and set at $0 \%$ as no microbial inhibition occurs. Experiments were carried out in triplicate.

from explanted voice prostheses (Table 3). The crude biosurfactant and fraction $\mathrm{C}$ exhibited an anti-adhesive effect against all microorganisms tested, but the anti-adhesive effect is dependent on the concentration and microorganism tested. For both crude biosurfactant and fraction $\mathrm{C}$ the highest anti-adhesive activity was found against $S$. epidermidis GB 9/6, S. salivarius GB 24/9 and $S$. aureus GB 2/1 with inhibition percentages between $53 \%$ and $77 \%$.

\subsection{Antimicrobial activity}

The antimicrobial activity of the isolated fractions was evaluated at several concentrations and compared to a variety of bacterial and yeast strains isolated from explanted voice prostheses (Table 4). Fraction $\mathrm{C}$ was found to be an antimicrobial agent but, depending on the microorganism, there were different effective concentrations. It was found that fraction $\mathrm{C}$ shows

Table 4

Antimicrobial activity of fraction $\mathrm{C}$ isolated from the crude biosurfactant with different concentrations against several bacterial and yeast strains isolated from explanted voice prostheses

\begin{tabular}{llllll}
\hline Microorganisms & \multicolumn{7}{l}{ Fraction C (g/l) } & & \\
\cline { 2 - 6 } & 2.5 & 5 & 10 & 20 & 40 \\
\hline S. epidermidis GB 9/6 & \pm & \pm & + & + & + \\
S. salivarius GB 24/9 & - & \pm & \pm & \pm & + \\
S. aureus GB 2/1 & \pm & + & + & + & + \\
R. dentocariosa GBJ 52/2B & - & - & - & \pm & \pm \\
C. albicans GBJ 13/4A & - & \pm & + & + & + \\
C. tropicalis GB 9/9 & + & + & + & + & +
\end{tabular}

The experiments were scored as positive $(+)$ when growth inhibition was observed (no colonies formed); a ( \pm ) sign indicated some colonies formed within the zones; no growth inhibition was marked as negative (-). a high antimicrobial activity against $C$. tropicalis GB 9/9 even at low concentrations. At the highest concentration tested $(40 \mathrm{~g} / \mathrm{l})$ fraction $\mathrm{C}$ was active against all bacterial and yeast strains involved in this study, except for $R$. dentocariosa GBJ52/2B which formed some colonies within the fraction spots.

\section{Discussion}

Crude biosurfactant obtained from S. thermophilus A was physicochemically and biochemically characterized as a multicomponent biosurfactant, consisting of protein and polysaccharides which possibly contained bound phosphate groups. A fractionation procedure that allowed the recovery of active fractions was established by using hydrophobic interaction chromatography. The hydrophobic interaction chromatography was originally introduced as an effective one-step purification technique for lipid microamphiphiles and was found to be a versatile procedure for species separation and analysis [36]. Using hydrophobic interaction chromatography is possible to obtain fractions with different hydrophobicities; therefore three distinct fractions with increasing hydrophobicities were isolated as surface active compounds, as can be seen in Fig. 1. Fraction $\mathrm{C}$ exhibited mainly a hydrophobic character and was found to be the most surface active fraction isolated. Generally, biosurfactants are microbial metabolites with the typical amphiphilic structure of a surfactant, where the hydrophobic moiety is either a long-chain fatty acid, hydroxyl fatty acid, or $\alpha$ alkyl- $\beta$-hydroxy fatty acid and the hydrophilic moiety can be a carbohydrate, an amino acid, a cyclic peptide, a phosphate, a carboxylic acid or an alcohol, among others. Microbial surfactants are commonly differentiated on the basis of their biochemical nature, functional properties and microbial species producing them, thus further functional characterization was evaluated 
both for crude biosurfactant and isolated fractions. Crude biosurfactant and fraction $\mathrm{C}$ are efficient in comparison with synthetic surfactants, as sodium dodecylsulphate, for example, with a cmc of $2.9 \mathrm{~g} / \mathrm{l}$ and surface tension $37 \mathrm{~mJ} / \mathrm{m}^{2}$ [37]. Although the isolated fraction $\mathrm{C}$ was not as effective $(\mathrm{cmc}, 20 \mathrm{~g} / \mathrm{l}$ and surface tension of $36 \mathrm{~mJ} / \mathrm{m}^{2}$ ) as many of biosurfactants described in the literature, for example sophorolipids obtained from Torulopsis bombicola with a cmc of $0.082 \mathrm{~g} / \mathrm{l}$ and surface tension $37 \mathrm{~mJ} / \mathrm{m}^{2}$ [37], it should be noted that the biosurfactant studied here was not purified as much as that described in the literature.

Fourier transform infrared absorption spectra and X-ray photoelectron spectroscopy data obtained for the crude biosurfactant showed that it consists of a mixture of several compounds. For the isolated fraction $\mathrm{C}$ no proteins were detected in the infrared absorption spectra, and several stretch vibrations and absorption bands characteristic of polysaccharides were observed. In addition, the $\mathrm{N} / \mathrm{C}$ and $\mathrm{O} / \mathrm{C}$ ratios measured by XPS were in accordance with the FT-IR data, pointing to the presence of polysaccharides and no proteins. The higher percentage of carbon involved in $\mathrm{C} 2$ bonds and oxygen in $\mathrm{O} 2$ bonds leads to the suggestion that the material probably contains glycolipids. Busscher et al. [24] described the production of crude biosurfactant by $S$. thermophilus B as mixtures of various components, with a glycolipid-like component being the most surface active.

The use and potential commercial application of biosurfactants in the medical field has increased during the past decade. Their antibacterial, antifungal and antiviral activities make them relevant molecules for applications in combating many diseases and as therapeutic agents. In addition, their role as anti-adhesive agents against several pathogens indicates their utility as suitable anti-adhesive coating agents for medical insertional materials leading to a reduction of a large number of hospital infections without the use of synthetic drugs and chemicals [38].

Silicone rubber is among the most common polymeric materials used for the production of a large number of prostheses. However, silicone rubber prostheses, as for example the voice prostheses, present a major drawback that relies on the fact that the hydrophobic silicone rubber surface becomes rapidly colonized with a thick biofilm and in this perspective the anti-fouling improvement of the silicone rubber material is desirable. In general, the main goal is to modify the physicochemical properties of the surface in order to reduce the force of attraction between microorganisms and the surface of the biomaterial. For instance, strategies have been developed to increase voice prostheses lifetime, as for example, the conditioning of silicone rubber surfaces with biosurfactants to achieve specific antimicrobial and antiadhesive properties $[11,29,34]$. Nevertheless, the applicability of biosurfactants as coating agents in voice prostheses is dependent on their stability at different $\mathrm{pH}$ 's as saliva can exhibit $\mathrm{pH}$ variations according to the patient diet. Furthermore, although the biosurfactants are not fully inhibiting the adhesion of yeast (Table 3) they are killed (Table 4), so these biosurfactants can still be used to improve the anti-fouling characteristics of the silicone rubber material. Even though only one purification step was included in this study, fraction $\mathrm{C}$ was found to be an antimicrobial and anti-adhesive agent against microbial strains isolated from explanted voice prostheses. Since the downstream operations cost generally represents $50-80 \%$ of the total processing cost, much care has to be taken if further purification steps are to be conducted and a compromise situation must be achieved.

\section{Conclusions}

A glycolipid-rich fraction obtained from S. thermophilus A was found to be a potent anti-adhesive and antimicrobial agent against several microbial strains isolated from explanted voice prostheses. Further purification steps should be carefully analyzed as each purification step will increase the costs and decreases the amounts of biosurfactants recovered.

\section{Acknowledgments}

L.R. Rodrigues thanks F.C.T. (Portugal) for the doctoral grant SFRH/BPD/26064/2005. The authors acknowledge CACTI (Spain) for running the FT-IR experiments and Joop de Vries (University of Groningen, The Netherlands) for running the XPS analysis.

\section{References}

[1] K. Jenny, O. Kappeli, A. Fietcher, Appl. Microbiol. Biotechnol. 36 (1991) 5.

[2] M. Morikawa, H. Daido, T. Takao, S. Murata, Y. Shimonishi, T. Imanaka, J. Bacteriol. 175 (1993) 6459.

[3] M. Velraeds, H.C. van der Mei, G. Reid, H.J. Busscher, Colloid Surf. B: Biointerf. 8 (1996) 51

[4] B. Angelova, H.-P. Schmauder, J. Biotechnol. 67 (1999) 13.

[5] F. Ahimou, P. Jacques, M. Deleu, Enzyme Microbiol. Technol. 27 (2000) 749.

[6] J. Desai, I.M. Banat, Microbiol. Mol. Biol. Rev. 61 (1997) 47.

[7] H.J. Busscher, T. Neu, H.C. van der Mei, Appl. Microbiol. Biotechnol. 41 (1994) 4.

[8] H.C. van der Mei, B. van de Belt-Gritter, R. van Weissenbruch, F. Dijk, F.W.J. Albers, H.J. Busscher, Trans. IChemE 77 (1999) 156.

[9] H.C. van der Mei, R.H. Free, G.J. Elving, R. van Weissenbruch, F.W.J. Albers, H.J. Busscher, J. Med. Microbiol. 49 (2000) 713.

[10] R.H. Free, H.C. van der Mei, F. Dijk, R. van Weissenbruch, H.J. Busscher, F.W.J. Albers, Ann. Otol. Rhinol. Laryngol. 110 (2001) 946.

[11] L.R. Rodrigues, H.C. van der Mei, I.M. Banat, J.A. Teixeira, R. Oliveira, FEMS Immun. Med. Microbiol. 46 (2006) 107

[12] I.H. Pratt-Terpstra, A.H. Weerkamp, H.J. Busscher, J. Colloid Int. Sci. 129 (1989) 568

[13] M. Velraeds, B. van de Belt-Gritter, H.C. van der Mei, G. Reid, H.J. Busscher, J. Med. Microbiol. 47 (1998) 1081.

[14] G. Reid, Int. Dairy J. 10 (2000) 415.

[15] C. Heinemann, V. van Hylckama, D. Janssen, H.J. Busscher, H.C. van der Mei, G. Reid, FEMS Microbiol. Lett. 190 (2000) 177.

[16] C.G. van Hoogmoed, H.C. van der Mei, H.J. Busscher, Biofouling 20 (2004) 261.

[17] C.G. van Hoogmoed, R.J.B. Dijkstra, H.C. van der Mei, H.J. Busscher, J. Dent. Res. 85 (2006) 54.

[18] A. Bernheimer, L. Avigad, J. Gen. Microbiol. 61 (1970) 361.

[19] L. Thimon, F. Peypoux, J. Wallach, G. Michel, FEMS Microbiol. Lett. 128 (1995) 101.

[20] R. Maier, G. Soberon-Chavez, Appl. Microbiol. Biotechnol. 54 (2000) 625.

[21] D. Kitamoto, H. Yanagishita, T. Shinbo, T. Nakane, C. Kamisawa, T. Nakahara, J. Biotechnol. 29 (1993) 91. 
[22] Y. Uchida, R. Tsuchiya, M. Chino, J. Hirano, T. Tabuchi, Agric. Biol. Chem. 53 (1989) 757.

[23] Y. Uchida, S. Misava, T. Ankara, T. Tabuchi, Agric. Biol. Chem. 53 (1989) 765.

[24] H.J. Busscher, C.G. van Hoogmoed, G. Geertsema-Doornbusch, M. van der Kuijl-Booij, H.C. van der Mei, Appl. Environ. Microbiol. 63 (1997) 3810.

[25] T. Neu, H.C. van der Mei, H.J. Busscher, F. Dijk, G. Verkerke, Biomaterials 14 (1993) 459.

[26] H.C. van der Mei, B. van de Belt-Gritter, F. Dijk, H.J. Busscher, Cells Mater. 6 (1996) 157.

[27] S. Eerenstein, W. Grolman, P. Schouwenburg, Clin. Otolaryngol. 24 (1999) 398.

[28] G.J. Elving, H.C. van der Mei, H.J. Busscher, R. van Weissenbruch, F.W. Albers, Ann. Otol. Rhinol. Laryngol. 111 (2002) 200.

[29] L.R. Rodrigues, H.C. van der Mei, J.A. Teixeira, R. Oliveira, Appl. Microbiol. Biotechnol. 66 (2004) 306.
[30] M. Dubois, K. Gilles, J. Hamilton, P. Rebers, F. Smith, Anal. Chem. 28 (1956) 350.

[31] L.R. Rodrigues, A. Moldes, J.A. Teixeira, R. Oliveira, Biochem. Eng. J. 28 (2006) 109.

[32] C.J. Boonaert, P.G. Rouxhet, Appl. Environ. Microbiol. 66 (2000) 2548.

[33] S. Stepanovic, D. Vukovic, I. Dakic, B. Savic, M. Scabic-Vlahovic, J. Microbiol. Meth. 40 (2000) 175.

[34] L.R. Rodrigues, H.C. van der Mei, J.A. Teixeira, R. Oliveira, Appl. Environ. Microbiol. 70 (2004) 4408.

[35] G. Elving, H.C. van der Mei, H.J. Busscher, A. Amerongen, E. Veerman, Laryngoscope 110 (2000) 321.

[36] W. Fischer, J. Microbiol. Meth. 25 (1996) 129.

[37] C. Mulligan, G. Gibbs, Biosurfactants: Production, Properties and Applications, Marcel Dekker, New York, 1993.

[38] L.R. Rodrigues, I.M. Banat, J.A. Teixeira, R. Oliveira, J. Antimicrob. Chem. 57 (2006) 609. 